\title{
INSTITUTIONAL STRATEGIES TOWARDS IMPROVING HEALTH INFORMATION SYSTEMS (HIS) IN SUB-SAHARAN AFRICA
}

\author{
Solomon Berhanu Bishaw \\ University of Oslo, Norway
}

\begin{abstract}
The development of "Health Information Systems" (HIS) in lowincome countries have been on the agenda for the last three decades. Despite significant mobilization, however, little progress has been made in realizing improved systems. One among the popular reasons for such progress concerns the lack or unwillingness of some relevant groups of actors to participate in HIS initiatives. Such explanations often delimit participants to a project or organisation level, and scant attention has been paid to the institutional environment, web of values, norms, rules, beliefs, and taken-for-granted assumptions that has long been recognized to influence the day to day realities of organisational life. This chapter, drawing on an institutional theory of membership, and based on discursive data of more than a decade and half from a low-income county's HIS development endeavors, reveals institutional processes and pressures that constrain participation of relevant actors.
\end{abstract}

Keywords: Information systems, institutional perspective, participation, Africa

\section{Introduction}

The importance of "health information" to support improvements in healthcare systems of developing countries has been emphasized for more than three decades. Policies on strengthening "Health Information Systems" (HIS) have, accordingly, been constituted globally [22, 25] and nationally [24]. Conceptualizations and advocacy as to what HIS constitutes, why it is so important, and how HIS development and implementation might be conducted have been delineated [23, $13,10]$. Technical and financial assistance have been mobilized to materialize the same $[1,6,13]$. However, three decades of policy and resource support appear to have done little to improve the situation $[1,25,13]$.

One among the popular reasons for the limited progress made so far relates to the lack of, unwillingness, or superficial participation of relevant actors in HIS development endeavors. Too often constraints in human resource are to be blamed $[24,25]$; either knowledgeable individuals or the financial and organisational resources required to hire such individuals are beyond reach. In this line of 
argument, neither the types of expertise required nor the causes for such constraints are adequately explored; rather they are either overlooked or assumed and taken-for-granted. Then we have the politics of conflicting interests resulting in unwillingness, or superficial participation, of some relevant actors, for example, those "on the ground" in healthcare facilities, the policy makers "on the top" [7], and those among the different so called vertical health programs [6, 7]. Little effort was made, however, to account for the mechanisms or the ways such unwillingness was revealed. Furthermore, such explanations often delimit participants to a project or organisation level, which usually includes a subset of the potential stakeholders that might be affected by, and affect, the initiative.

There exists though, a wider recognition and frequent calls too, to broaden the sphere of research in the domain $[18,21]$. Walsham and Sahay, for example, have called for critical studies as a way to open up "black boxes" surrounding IS initiatives, and called for the deployment of institutional theory as "topics and issues in developing countries are normally deeply intertwined with issues of power, politics, donor dependencies, institutional arrangements, and inequities of all sorts" [21, p. 19]. Smith and his colleagues also have suggested that "there is a need to first of all gain understanding of the existing social structures in place and then to carefully interpret to what extent and through which means participation of marginalized groups can be made possible" [18, p.16].

In this chapter, we aim to examine institutional processes and pressures that constrain, construct, and empower organisational or individual actor's participation in HIS development endeavors. We draw on "the institutional theory of membership", which emphasizes that participation in a specific domain by organisational or individual actors is seen not as a choice among unlimited options determined by purely internal arrangements, but rather as a choice among a narrowly defined set of legitimate actors determined by members composing a wider community [12]. By employing such a theoretical framework, I hope to deepen understanding, and stimulate appropriate action.

Section 2 provides the main constructs of the theoretical framework that guide the study. In section 3, we discuss the research context and the methodology employed. Section 4 presents construction of our analysis. Section 5 considers implication and limitations of the study.

\section{Theoretical framework}

This study employs the institutional theory of membership [12] as an analytical lens to examine institutional processes and pressures that constrain, construct, and empower organisational or individual actors' involvement in HIS development endeavors. The notion of membership describes the basis of legitimate participation in a social arena [12]. Legitimacy here is "a generalized perception or assumption that the actions of an entity are desirable, proper, or appropriate within some socially constructed system of norms, values, beliefs, and definitions" [19, p. 574]. Central to the institutional theory of membership, accordingly, is its 
emphasis that organisational or individual actors are involved in a given social phenomenon is seen not as a choice among unlimited array of possibilities determined by purely internal arrangements, but rather as a choice among a narrowly defined set of legitimate actors determined by the members composing the organisational field. The form of this influence is manifested in membership structures: pragmatically oriented sets of rules that delineate membership, explaining who can participate and who can not in a given social arena, and if allowed to participate with what social position $[12,11]$.

Organisational field refers to the idea that a distinct "set of organizations" that comprises sets of "subject positions" (posts) bound together by institutionalized rules and standards [12, 8, 5]. This "set of organizations" represent "those organizations that, in the aggregate, constitute a recognized area of institutional life: key suppliers, resources and product consumers, regulatory agencies and other organizations that produce similar services or products" [8, p.148]. And for Bourdieu fields "present themselves synchronically as structured spaces of positions" [4, p. 72] cited in [12]. While the rules of membership that structure organizational fields reward particular strategic positions and practices, it also sanctions others, which makes the constitution of membership rules dynamic. Organizational and other actors continuously struggle to interpret or change membership rules so that their own identities are privileged [12].

\section{$2.1 \quad$ Interaction rituals}

Lawrence [12] argued that "membership in professional fields is produced through and enacted within sets of "interaction rituals"' [12, p. 118]. Interaction rituals are "routinized interactions between two or more actors that are vested with some symbolic significance" [ibid]. For example, business lunches with colleagues, formal presentations at professional meetings, graduation ceremonies, or meetings of audit teams may represent interactive rituals.

Interaction rituals that govern membership can vary in terms of the degree to which they are formalized and taken-for-granted; or with respect to the actors involved. In this latter case, interaction rituals may involve relatively homogeneous sets of actors or in contrast, membership may be negotiated among a heterogeneous set of actors including multiple professional groups and clients. Membership is, therefore, conceptualized as a product of interaction ritual chains in which actors co-construct relationships with each other and membership boundaries. At the same time, membership boundaries produce the social space in which particular interaction rituals are understood as meaningful and valuable. Actors, therefore, through participation in these rituals, negotiate and signal their institutional membership [12].

As Lawrence [12] argued, neither the experience of membership nor its basis in interaction rituals is a simple, binary phenomenon. The social boundaries of some groups distinguish members sharply and powerfully from non-members, whereas for other groups the distinction is less clear and distinct. These differences reflect 
the way the interaction rituals vary in intensity and the extent to which they are self-reproducing. Fields with strong, enduring boundaries are built from powerful, self-reproducing rituals.

\subsection{Membership strategies}

Lawrence [12] argues that membership definitions of a field are of strategic interest to affected organisations and individuals. In a professional field, he argues that the interaction rituals define the boundaries of the profession by structuring the relationships among professionals, clients, regulators and other stakeholders, and also structure the distribution of the field's economic interests.

Membership in professional field is inherently dynamic, as membership boundaries can engender strategies of resistance in the part of those less privileged by the boundaries, who are often those excluded by the membership boundaries (See Figure 1). Social boundaries effectively associate various forms and amounts of "capital" with particular subject positions in the field [5]. Capital includes a diverse range of resources, including educational qualifications, social networks, and legitimate authority as well as economic capital. The differential allocation of capital based on the boundaries of institutional field sets up a situation in which conflict is embedded in their structures; actors will work to gain access to privileged positions or attempt to enact new rituals in order to change institutional rules and redistribute capital $[5,12]$.

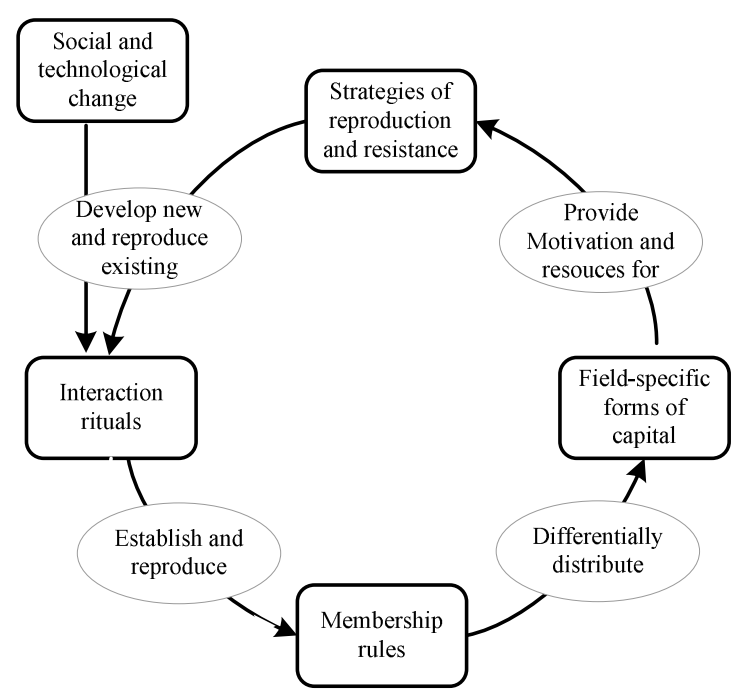

Figure 1: Membership dynamics in institutional fields (Source: [12, p. 122]).

Membership of professional fields may be transformed either through the impact of external disruption or through the strategies of interested actors. 
Lawrence [12] argued that the starting point for understanding these dynamics is the set of interaction rituals that affect the membership rules for the field and in so doing differentially distribute the capital produced and motivate actors to reproduce or resist those rituals. A key issue then concerns the ways in which actors attempt to create new interaction rituals in order to reorient this process.

\section{Research approach}

\subsection{Research context and the HIS organisation field}

This case study is based on Health Information System (HIS) development endeavours of a country located within the Sub-Saharan Africa. The modern healthcare system of the country has evolved over six decades as to its intra- and inter-organisational relationships, among other things. Internally, the organisational structure of the healthcare system has evolved with encounters between integration and separate health programs as well as centralization and decentralization. Externally, the system, being situated within a deprived economy, depends on others who are willing to augment the resources of the government to its operations. Since the outset, the system has been getting support from bilateral and multilateral agencies each of which have their own preferences as to the organisation and reporting mechanisms that has to be followed.

The introduction of what is known as the Sector Wide Approach to the health sector in the mid 1990s has bring such intra- and inter organisational relationships into the forefront through the structured consultations and documents produced through the process. One among the issues embedded in such encounters has been the development of HIS. While proprietary data collection and reporting systems persist all along for almost each separate health program, a department has been taskedllegislated to lead the development of an improved HIS system, at least since the end of the 1980s. The focus of this study to examine the institutional processes and pressures that constrain, construct and empower participation of various actors in HIS development endeavours this period.

Six relevant actors were identified in the HIS organisational field. Two groups are from within the Ministry of Health $(\mathrm{MoH})$ : the Planning Department and the "Other Departments". The Planning Department is the responsible division for the HIS function, initially informally and latter formally. Within this department there has been a unit, some times known as Health Statistics Unit and at times the HMIS unit, with a total of five posts two of which were professional at the end of 2006. The "Other Departments" within the MoH include Disease Prevention and Control (DPC), Environmental Health, and Mother and Child Health (MCH). Each of these departments has separate health programs such as Malaria and HIV \AIDS within the DPC; EPI and Family Planning within the MCH, and specialist experts. The third actor is the WHO, which is deeply embedded in the healthcare system. The WHO's staffs in the Country Office have increased from 3 to about 100 through a period of about half a century. The forth group represents Donors 
supporting the health sector broadly (more than two dozens) and the HIS component in particular. The other two groups are a public health group (which includes a private consultancy company and an academic department); and an Information Systems (IS) academic group.

\subsection{Methodology and methods}

This study employs Critical Discourse Analysis [15]. Discourse is defined as "an interrelated set of texts, and the practices of their production, dissemination and reception, that bring an object into being" $[15$, p. 3$]$. Texts are considered here to represent spoken, written, or any kind of artifacts that can be systematically investigated [15]. Discourse analysis as a methodology is used here to make sense of the processes whereby reality comes into being by examining and connecting individual texts to discourses, and locating both within a historical and social context. As our interest in this study rests on institutions, membership structures specifically, we rely on the discursive model of Phillips, Lawrence and Hardy in claiming that "institutions are constituted by the structured collections of texts that exist in a particular field and that produce the social categories and norms that shape the understandings and behaviours of actors" [16, p. 638]. We also base our data collection and analysis efforts in their suggestion that "particular discourses and institutions that affect an organization or sets of organizations could be studied historically, by tracing them back to key texts" [16, p. 647].

There were two distinct phases of data collection. The first of these was the gathering of "naturally occurring" key texts regarding the HIS under consideration. Two sets of texts were identified in this phase. The first set of texts relates to a long term (20 years) comprehensive Health Sector Wide Program, which covers all aspects of policy and planning, implementation, monitoring and management of all the areas that relate to the provision of healthcare to the whole country. Specific texts in this category include short-term (5-year) Sector Wide Programs (SWP), program action and implementation manuals, implementation performance reports, joint review meeting proceedings, and commissioned thematic consultancy reports. As HIS (also known as HMIS) together with Measurement \& Evaluation being one among seven major components of the SWP, it has persistently been in the discourse in the iterative processes of planning, implementation, and evaluation. These texts collectively, and in a structured way, have left traces of more than a decade of experience in the sector. The second set includes HIS related texts produced before or during the SWP, but more or less independently from it. These include texts produced on pilot initiatives since 1990 and HIS related publications of the WHO and associates, particularly texts that were projected to the African Regional Office and Member States. The second phase of data collection involved web site visits and interviews with two senior staffs of the Ministry of Health $(\mathrm{MoH})$. The focus of this phase was to gather background data on the different groups and individuals identified in the previous phase as to their place in the HIS field. 
Data analysis was guided by the theoretical framework outlined in the previous section. Given the research focus on membership structures and strategies, we first examine each text in the discourse for traces of prescriptions for, or enactments of interaction rituals and their participants; strategies employed by the identified actors to introduce, reproduce or transform the rituals; the type of relationship among actors as to the coalition and competition as well as the resources available to each group. Backgrounds of individuals participating in the different rituals were explored as to their education, work experience, and organisational affiliation. Such background was sought besides the texts within the discourse, from websites associated to the different groups, and interviews with two senior employees at the $\mathrm{MoH}$.

Finally, my extended involvement in the research domain needs to be mentioned here, which has enabled me to have a close look to the evolving interests and positions of the different actors in the field. I started involvement in the domain around mid 2003 with extensive visits to become acquainted with the government health care system broadly and HIS activities in particular. Over the subsequent one and half years, I was involved with a group of IS action researchers in initiating and enacting collaboration with authorities at autonomous "Provincial Health Departments" and undertaking pilot projects towards the development of an improved HIS in their constituencies. Over the latest three years, I have directed my attention and commitment to broader issues mainly following developments in the domain closely with a role of independent observer. In the entire five years, I was in the country for about twice a year and for an average of about six weeks each time. Prior to my entry into this research domain, I was mainly engaged in teaching and practicing Systems Analysis and Design as well as Database Design for about four years.

\section{Membership structures and strategies in the HIS field}

\subsection{Interaction rituals}

The emergence of the HIS field in the country can be linked to the WHO and its recent development to the Sector Wide Program (SWP). This section presents the interaction rituals in more or less chronological order in three distinct periods: the early period before the introduction of the SWP; the formative years of the SWP; and the maturing SWP.

In the early period, two sets of interaction rituals dominate the HIS field under the sponsorship of the WHO. At the international/regional level major interaction rituals include consultative workshops such as study groups, technical discussion sessions, and workshops to develop, as well as disseminate, conceptualizations on HIS. One example of such early ritual is the technical discussion on "Strengthening Information Support for Management of District Health Systems" at the end of the 1980s. Participants in such rituals include the WHO and 
associates mostly public health academics and practitioners as well as authorities at the Ministries of Health of member countries.

At the country level, major interaction rituals include consultations, committees, and workshops. Consultations among officials of the WHO and the $\mathrm{MoH}$ were instrumental in the initiation of, and recruitment of a consultant for the pilot project, named "Strengthening District HMIS in [the country]", in 1990-91. Representatives of the WHO, as members of Policy Task Force or as "Resource Person" also did consult the $\mathrm{MoH}$ as in the inclusion of an HMIS provision in the Health Policy as well as in the SWP. Members of such consultation were mainly those responsible employees at the $\mathrm{MoH}$ and the responsible officers at specific departments within the WHO Country Office, but also consultants from the Regional Office and the Headquarters as well as funding agencies.

During implementation of the early mentioned pilot project, two committees and a series of consultative workshops were proposed and enacted. The two committees were a Technical Working Group (TWG) and a National Advisory Committee (NAC). The TWG was "established to prepare an implementation plan and to assume responsibilities for implementation". While it was lead by a "Statistician" responsible for the health statistics unit within the Planning Department $\backslash \mathrm{MoH}$, other named member also includes a "Statistician" from the Provincial Health Department' where the pilot districts were located. The NAC was proposed and constituted to support the TWG on "policy issues". This was said important because "on policy issues, the TWG had minimal leverage in negotiating with relatively well-financed vertical programmes". Accordingly, as reported by the WHO consultant, the committee was constituted with departmental and programme heads from the Ministry of Health and allied institutions, and were officially inaugurated with the presence of the Vice-Minster for Health. Besides these two committees, a series of workshops was proposed and at least a couple of them were enacted throughout the project period (in 1990-91). The objective of the workshops was to create a common understanding on issues surrounding district HMIS. Participants of such workshops were employees of the health care system, mainly from district health offices. For example, in the first consultative workshop there were 62 participants and 3 observers representing 18 districts, a Provincial Health Department, the MoH, the WHO and a donor agency, who had supported the project financially through the WHO.

Following the introduction of the SWP, two sets of interaction rituals, focusing on governance and evaluation, were introduced. The governance rituals comprise a set of structured "consultation forums" and "joint decision-making" framework which was developed and formalized over a decade. These structured rituals constitute, from top hierarchically, a Macro and Sector Level Joint Steering Committees, Intermediary Sectoral Consultative Forum, and Technical Coordinating Committee. The top level rituals often enacted once or twice a year and with a focus on policy issues; the intermediary level enacted once every two months and with a focus on operational and managerial issues; and the Technical Committee meets in almost a weekly basis focusing on implementation issues. 
Membership in these rituals constitutes representatives of the Government and Donors fundamentally and often evolved to have more donor representatives than the government counterparts. The Technical Committee, for example, was set to include nine members four of which were set to the government. However, throughout the years there was only one member representing the government, head of the Planning Department, while at least five members represent donors. The chairmanship of this Committee has also been shared jointly by the head of the Planning Department and the WHO.

Each of these rituals has its own developmental history. If we take the Technical Committee, it was no where at the beginning of the SWP. At about midway in the implementation of the first five-year SWP, two individuals representing donors and the government coordinate a mid term review process together with "resource persons" from the WHO and another donor agency. This was to support the "inadequately staffed" and "highly overloaded" Secretariat of the SWP, the Planning Department. Subsequently, the Technical Committee was emerged informally to coordinate review missions, supporting recruitment of consultants, among other things, during the second SWP. In the third SWP, this Committee becomes formally embedded in the formal governance structure of the sector. As per a recent memorandum of understanding among some group of donors and the government on a certain Fund, "the [Planning Department] is responsible for receiving, processing and approving requests for funding, and ensure the appropriate and efficient use of the Fund in the spirit of its purpose. [Technical Committee's] endorsement is needed ... for activities which exceed the agreed budget".

The evaluation rituals are for "assessment of activities surrounding [SWP] implementation including monitoring of key performance indicators, periodic reviews, and joint donor supervision missions and thematic and evaluation studies". Four rituals can be identified in this category: frequent Joint Review Missions, Mid-Term and Final Evaluations, and ad hoc commissioned thematic studies. Evaluation rituals are said to be conducted "by specialists who have not been involved in the day-to-day management of a program" and with an "appropriate mix of national, international, Government and Donor personnel" and with a special preference to specialists already familiar with the domain.

If we consider, for example, one of two final program evaluations conducted so far, there were a total of 43 professionals participated from across various organisations (constituted into eight teams HMIS being one): 11 from the public sector; 23 from donor agencies; 1 local NGO representative; and about 8 individual consultants. Among a total of 12 expatriates participated in the evaluation was the team leader for the HMIS component hired for short term assignment from abroad. As per self-declared profile, the consultants' educational background, experience, as well as interest constitute a wide area of public health specialties: human nutrition, statistics, medical sociology; health systems research and development; health policy; monitoring and evaluation; health management information systems; and health financing. Other frequent participants in the 
HMIS evaluation sub-team hold such positions as "health specialist" or "health sector development specialist" in multilateral and bilateral donor agencies. Such team members have been swapped to evaluate other components such as finance strategy or health services in different evaluation missions.

After about half a dozen of years since the implementation of the SWP was launched, and the governance and evaluation rituals maturing, calls were made to constitute, once again, the traditional rituals, namely the Technical Working Group (TWG) and the National Advisory Committee (NAC), which were enacted after a year and half latter. This time, the NAC was established "with a view to facilitate the development of a national policy and strategy on HMIS and M \& E". Membership to the NAC was explicitly proposed to include representatives of the $\mathrm{MoH}$, donor agencies, and an NGO initially; and "at a latter stage private sector and institute of higher learning"; and was enacted accordingly. The initial members of the NAC procured an international consultancy service for "Strengthening the National HMIS and Monitoring \& Evaluation". Subsequently, the private consultancy company, who won the international bid, and an academic public health group who was tasked to handle the training component of the consultancy work have joined the ritual. Finally, an IS group from an informatics department of a university, who has competed and lost the consultancy bid, had joined the NAC.

The TWG was then proposed not only "to provide technical advice, and to monitor the implementation of the activities of the HMIS and M\&E reform", but, since various stakeholders "have shown interest in supporting specific activities in different areas of the national HMIS and M \& E reform (i.e. ICT, training etc)", it also has "to insure coordination between the institutions and synchronization in executing their respective, complementary activities". Membership into the TWG was, accordingly, been proposed to constitute the public health consultancy company, the public health academic group, the IS academic group, and a Foundation which has been involved in "Hospital Management Information Systems" in parallel but independently.

\subsection{Membership strategies}

Different strategies have been employed by the groups identified earlier in the construction, reproduction or transformation of the rituals in the field over the years. The WHO has been at the center of the field since the beginning and has influenced the rituals over the years as in many technical facets of the sector. The WHO, primarily had developed (through its own staff and collaborators) conceptualizations about HIS, embedded are - among other issues - the requisite expertise to participate in HIS related work and the location of professionals with such expertise both globally and within member states. While the expertise found within the WHO was emphasized, specific divisions within the WHO and collaborating centers were mentioned as sources of such consultants. At the country level, it was said that "emphasis should be placed on enhancing existing 
service staff and manager capacities in data generation, analysis and use, including the use of computers, rather than creating specialists in health data analysis and informatics". The WHO also employs its direct and well established relationship with the $\mathrm{MoH}$ to introduce, realize, and sustain its prescriptions. If we take the 1990191 "District HMIS" pilot project, while the WHO had hired an expatriate consultant with the stated expertise to lead the project, "Epidemiology Coordinators (trained sanitarians)" were selected and trained from local staff for the "Information Coordinator" position. The latter were selected because of their "practical experience in relating numbers to decisions", "statutory responsibilities for management information systems", and for "being members of district health teams". Finally, the WHO advocates and facilitates adoption of resolutions on strengthening HIS by the World Health Assembly including its' own role in the field when and if needed. The latest resolution adopted in May 2007, besides once again reiterating the importance of HIS, notifies "the constitutional normative mandates of WHO in health information and epidemiological reporting" and requested the executive body "to increase WHO's activities in health statistics at global, regional and country levels and provide harmonized support to Member States to build capacities for development of health information systems and generation, analysis, dissemination and use of data".

Donors have employed Colonization strategies, which are "aimed at effecting a subject position within a field that gains its legitimacy and influence through its connection to positions outside the field". The SWP championed by the World Bank in mid 1990s was the basis for changes adopted by donors supporting the health sector. In subsequent years, three major processes were adopted by donors. First, the necessary conceptualizations for the health SWP including the major components of the program, governance structure and consultation forums, key documents and schedules were developed, and continuously refined. Secondly, Donors have managed to forge, formalize and institutionalize strong alliances among themselves. Also known as Donor's architecture, comprises a hierarchical, from a high level Donor Group (composed of head of missions for multilateral and bilateral donors), to Sector level Working Groups (Health Sector Donor Group is one among a dozen), to thematic Sub-Groups (HMIS being one among more than twenty), which was build over a decade. These were then have to join with government counterparts in creating the "joint consultation" and "decisionmaking" rituals, which were described in the previous section at least partly. Donors, as part of the alliance, are then expected to "speak with one voice" during consultations with their government counterparts as adopted by them as part of their "ways of working". Thirdly, donors embed and enact conditionality in their engagement with all concerned and the government in particular. For example, it was reported in one of the annual SWP performance reports that donors "were preparing to scale up their assistance... However, as a result of the [unacceptable] events in [year], donors have undertaken a joint-assessment of political and economic conditions for development. Also, they have suspended direct budget support". 
The Public Health Group has employed stratification strategies that "involves the development or reformulation of interaction rituals into hierarchical chains such that professional groups in the field relate to each other through a series of order-giving and order-taking exchanges" [12, p. 136]. The public health consultancy group has created such a hierarchy when it hired local software developers in two occasions over the last five years. Earlier, two individual software developers were recruited for an autonomous provincial health department as part of a wider technical assistance, and very recently a software development company was subcontracted. In both cases, the developers were instructed to create "electronic version" of the data collection and reporting formats from page layout and formatting to positioning of selectable options. Similarly, at least initially, the public health academic department was tasked to participate in the training component of the HMIS consultancy work. In this regard, the public health academic group has mobilized and initiated a post graduate program in "Measurement and Evaluation", and "preparations are underway to begin diploma level training on HMIS... to support the new system with a sustainable human resource base".

The IS group employs association strategies, "which involve attempts to develop interaction rituals in which less established professional groups become engaged in common sets of activities and routines with more established groups" [12, p. 134]. This is to create and change "subject positions so that positions they are capable of occupying gain legitimacy from previously legitimated positions" [ibid]. The IS group has attempted a serious of activities in this regard. First, alliances were established with public health departments within universities, autonomous provincial health departments, and individual public health professionals. At the forefront of these activities was the collaboration with some autonomous provincial health departments to pilot test software for use in their constituencies. Such initiatives, however, had triggered such a comment during evaluation rituals “... uncoordinated provincial initiatives have been implemented to improve data collection and reporting; while well-intentioned, these initiatives threaten to further fragment an already fragile system". Secondly, efforts were made to introduce new rituals such as workshops, graduate level programs, and publications. Workshop tracks were organized on HIS in a mega continental ICT conference and another in a national ICT-for-health workshop. In these rituals invited participants, and panelists, include officials of the MoH/PD and Public Health Academics together with IS groups, the organizers. A call was made by this group in these workshops for a successive ritual for "sharing of best practices, know-how and software" among the different initiatives that were going on in parallel within the country. A graduate level program in HIS, another ritual, granting admissions to students from public health and informatics background, alike, was also introduced. Members of the IS group were also involved in proposal development and publishing articles together with public health professionals. 
Last, but not least, we have the two groups within the Ministry of Health: the Planning Department and the "Other departments". The planning department, being in the center of the field, has all along been engaged with the WHO and donors intensively as well as with the new actors to a lesser degree despite its limited capacities. No traces of a unique kind were found in the discourse except the enactment and reproduction of existing prescriptions by this group. What was more is the participation of this group in other rituals (workshops and conferences), locally and abroad, with groups either at the periphery, or outside of the HIS field as has been constructed locally. In this rituals as well, this group reflects the prescriptions embedded in the HIS field. In a workshop organized by three ICT related departments of the national university and a government telecom company to deliberate on the challenges and prospects of appropriating ICT in the health sector, a senior staff from this department, who spoke on "Future Prospects on Telemedicine \& HMIS", had emphasized that "support and technical assistance are expected from WHO in ICT area".

In the contrary, the "other departments" within the $\mathbf{M o H}$ has been taking the strategy of resistance by boycotting the rituals all along. Traces of such action are in abundant both in the rituals and in pilot implementation initiatives. As a recent SWP final evaluation emphasized "the participation of $\mathrm{MoH}$ in some of these joint arrangements ... seems to have been reduced to few staff from the Planning Department rather than the broad spectrum of $\mathrm{MoH}$ leadership. A broader and stronger representation of the $\mathrm{MoH}$ led by Planning Department would lead to a more effective Government-donor policy dialogue". It was also reported that among the factors to have constrained progress in HIS were "that several programs are coordinated by departments who all wish to monitor progress and performance in their own respective domains". Similarly "resistance" or "unwillingness" of members of this group in micro activities as in limiting "indicator" requirements, or using the new HMIS tools were many. In response to such resistance, the latest performance report of the SWP has revealed, that "preparation of legislation is underway in order to enforce the implementation of the new system."

\section{Discussion and implications}

The empirical case presented in this study depicts the construction and transformation of membership structures in the HIS field and the varying strategies employed by the constitutive actors. We would argue that there has been membership structures in the HIS field that constrain some core groups of actors from participation. We also argue that the strategies employed by the various groups have failed to mobilize the necessary skills and support towards an improved HIS. In what follows a brief discussion on these issues is presented followed by highlights on the limitations and implications of the study.

Membership in the HIS field has been delineated almost exclusively to health related professionals as well as expatriate experts and with previous experience. In 
the early period, professionals within the WHO system and associates were the dominant sources of expertise. Through the SWP, new rituals have been introduced providing the basis for the ascendance of donors to the central position; existing rituals were then redefined to allow entry for new actors - private and academic public health groups and individuals. Furthermore, over the years, HIS related consultancy services have been exclusively directed to international consultants. Previous involvement in similar initiatives has also been preferential.

The strategies employed by the different groups have had mixed outcomes; but donors, and those backed by them, eventually shaped the membership structures significantly. The WHO, and the Planning Department of the MoH, both of which have been stayed central in the field reproduced the membership structures repositioning themselves as per the institutional dynamics. The "other departments" within the $\mathrm{MoH}$ have also persistently rejected to enact membership without any effect on the membership structures. Donor's colonization strategy, on other hand, has succeeded in transforming the membership structures facilitating entry for non-traditional actors such as for the private consultancy company. This could be attributed to their possession over scarce resources. Similarly, the stratification strategy of the public health consultancy group was also successful as they have managed to create hierarchical chains restricting directly or indirectly - the IS professionals' access to field level rituals. Their success can be attributed primarily to their ability to influence donor(s) which could overcome any resistance from other groups, but also the enabling membership structures and their previous engagement in the broader health sector.

We also argue that the IS group's association strategy has had limited success so far. This group has been excluded from rituals in the field despite its visibility and interest. Its recent inclusion into a ritual is only at the periphery, after the issues surrounding HIS has been framed and almost all decisions have been made. Two explanations could be speculated as to the underlying reasons for the limited progress. First, since this group emerged after decades of institutionalization of membership structures, and after the governance and evaluation rituals of the SWP has more or less "stable and broadly acknowledged centers, peripheries, and status orders" [12, p. 135] the existing institutional structure is "less conducive to the construction of new positions or the transformation of existing ones" [ibid]. The second reason could be the inability of the IS group to offer a species of capital not readily available in the field as it is currently structured [12]. The latter reason could be attributed, at least partly, to the constraining institutional context.

To return to the issues raised at the beginning of this chapter, lack, unwillingness or superficial participation of relevant actors needs to be revisited and informed through the institutionally defined membership structures. In particular, I wanted to emphasis the cognitive and normative effects [19] of the membership structures. The cognitive aspect of membership structures makes actors unable to conceive different options as far as recruitment of professionals (organisational or individual) is concerned. Failing to recognize such options, they naturally also fail to act on them. One apparent example is the uncritical demand 
for support from the WHO in ICT matters in healthcare as presented by a senior representative of the Planning DepartmentlMoH in a national workshop mentioned in the previous section. Such articulation considers neither the potential for collaboration with the ICT elites (academics and practitioners) who were present in the workshop with such a purpose nor the level of competence that can be found from the WHO in this domain. Prior research, however, identifies that the WHO has "a remarkably homogenous work force" with professional staffing "concentrated in medicine and public health" [14, p. 737] and has not made investments in ICT and related strategies [2] even for its own organisational use.

Membership structures also have normative aspect where actors conform to prevailing "appropriate" prescriptions. This is not only because the prescriptions might be proper or preferable, but also because of the awareness as to the incentives andlor disincentives that may follow for conformance or nonconformance. In the one hand, even when some of the actors participating in the field do perceive the need to include other professionals (with such backgrounds as IS or its reference disciplines) into the rituals, they may be reluctant to entertain such options because accepting existing membership structures that enjoys normative status may enhance their professional andlor organisational legitimacy, improving chances with interests that control important resources such as financing, professional labour, and managerial appointments and promotions [26]. On the other hand, even those disadvantaged groups such as the IS group or local professionals may prefer conformance to the prevailing membership structures against a sort of open dispute or demurring the existing membership structures. One possible explanation might be the costs that could be incurred with such act, in particular withdrawal of support for example in funding, or access to constituents. Individual andlor organisational interests may, then, best be served by following the crowd even if this is suboptimal (and even seems unacceptable at times) when considered merely on the basis of professionalism.

In another twist, the persistent boycotts of the "other departments" within the $\mathrm{MoH}$ to enact their membership in the HIS field could be interpreted as unwillingness to grant legitimacy either for the propriety of the HIS activity in general or for the validity of the constituting actors as practitioners [19]. This group may be unable to comprehend integrated HIS because of their entrenched cognitive frames through the separately managed health programs; or even if they do comprehend, they may not perceive the HIS field as it has been structured all along as valid and desirable (normative legitimacy); or as mentioned earlier, even when they do perceive the field's desirability, they may be reluctant to implement them because of their awareness of the risks of loosinglreducing their organisational power. The recent plan to impose this group to participate in the field through ratification of legal requirement is unlikely to succeed [20].

As a concluding remark, I suggest a collective effort to identify and transform such constraining structures in the field as a matter of priority. One way to do so is through theorization: the challenging of extant structures, the reasoned analysis of the limitations and latent possibilities of existing social patterns, the framing of 
alternatives, and mobilization of resources for the social construction of those alternatives [9, 17]. This may help actors, in this case, to perceive the requisite expertise to develop information systems, but could also be instrumental in defusing self-interested opposition. Finally, I would like to remind the suggestion made by Baskerville and Myers that the IS discipline has "a tremendous opportunity to take a prominent, leading role within the larger community of scholars interested in the development, use, and impact of information technology and systems in broadly defined social and organizational settings" [3, p. 8]. The health sector of low-income countries is one such arena.

The study has two limitations. First, the focus has been on the dominant voices in the field. Limited attempt was made to present dissenting voices within and across groups when traced. Neither the WHO nor the $\mathrm{MoH}$ are homogeneous; neither are donors and academics. Second, the discussion in this chapter is limited only to one "HIS" field, the one concerned with integration, implicitly or explicitly, and its discourse(s); other neighbouring and conflicting fields and their discourses were not examined.

Despite such limitations, however, this study has implications for research and practice. For practice, this chapter has shown not only the existence or effects of membership structures that needs to be considered in IS development endeavours, but the conception of such structures as socially constructed, and consequently manageable opens up strategic possibilities for IS practitioners and policy makers alike. For research, this chapter shows, focusing on a single institutional structure, that deepening understanding in such domains as IS in developing countries, necessitates the examination of the institutional context more than the actors in a single project or organisation.

\section{References}

[1] AbouZahr, C. \& Boerma, T. (2005). Health information systems: The foundation of public health. Bulletin of the World Health Organization, 83(8), 578-583.

[2] Barrett, M, Fryatt, B., Walsham G., \& Joshi, S. (2005). Building bridges between local and global knowledge: New ways of working the World Health Organization. KM4D Journal, 1(2), 31-46.

[3] Baskerville, R. \& Myers M. (2002). Information systems as a reference discipline. MIS Quarterly, 26(1), 1-14.

[4] Bourdieu, P. (1993). Sociology in question. London: Sage.

[5] Bourdieu, P. \& Wacquant, J.D. (1992). An invitation to reflexive sociology. Chicago, IL: University of Chicago Press.

[6] Braa, J. Eric, M., \& Sahay, S. (2004). Networks of action: sustainable health Information Systems across Developing Countries. MIS Quarterly, 28(3), 1-26.

[7] Chilundo, B. (2004). Integrating information systems of disease-specific health programmes in low income countries. Unpublished $\mathrm{PhD}$ Dissertation, Oslo: University of Oslo.

[8] DiMaggio, P. J. \& Powell, W. W. (1983). The iron cage revisited: institutional isomorphism and collective rationality in organizational fields. American Sociological Review, 48(2), 147-160. 
[9] Greenwood, R., Suddaby, R. \& Hinings, C. R. (2002). Theorizing change: The role of professional associations in the transformation of institutionalized fields. Academy of Management Journal, 45(1), 58-80.

[10] HMN/WHO (2008). Framework and standards for country health information systems. http://www.who.int/healthmetrics/documents/hmn_framework200802.pdf. Accessed 20 April 2008.

[11] Lawrence, T. (1999). Institutional strategy. Journal of Management, 25 (2), 161-188.

[12] Lawrence, T. (2004). Rituals and resistance: membership dynamics in professional fields. Human Relations, 57 (2), 115-143.

[13] Lippeveld, T., Sauerborn, R., \& Bodart, T. (Eds.). (2000). Design and implementation of health information systems. Washington DC.: World Health Organization.

[14] Peabody, J. W. (1995). An organizational analysis of the World Health Organization: narrowing the gap between promise and performance. Social Science and Medicine, 40(6), 731-742.

[15] Phillips, N. \& Hardy, C. (2002). Discourse analysis: investigating processes of social construction. Thousand Oaks, CA: Sage.

[16] Phillips, N., Lawrence, T., \& Hardy, C. (2004). Discourse and institutions. Academy of Management Review, 29(4), 635-652.

[17] Seo, M., \& Creed, W. E. D. 2002. Institutional contradictions, praxis, and institutional change: A dialectical perspective. Academy of Management Review, 27(2), 222-247.

[18] Smith, M.L., Madon, S, Anifalaje, A., Lazarro-Malecela, \& M., Michael, E. (2008). Integrated health information systems in Tanzania: experience and challenges. EJISDC, 33(1), 1-21.

[19] Suchman, M. C. (1995). Managing legitimacy: Strategic and institutional approaches. Academy of Management Review, 20(3), 571-611.

[20] Tolbert, P. S. \& Zucker, L. G. (1983). Institutional sources of change in the formal structure of organizations: the diffusion of civil service reform, 1880-1935. Administrative Science Quarterly, 28(1), 22-39.

[21] Walsham, G. \& Sahay, S. (2006). Research on information systems in developing countries: current landscape and future prospects. Information Technology for Development, 12(1), 7-24.

[22] WHO. (1978). Development of health information systems, Thirty-First World Health Assembly Resolution (WHA31.20).

[23] WHO. (1993). Guidelines for the development of HMIS. WHO Regional Office for the Western Pacific, Manila.

[24] WHO. (2006). Health of the people (The): The African regional health report.

[25] WHO. (2007). Strengthening of health information systems, Sixtieth World Health Assembly Resolution (WHA60.27).

[26] Zucker, L. G. (1987). Institutional theories of organization. Annual Review of Sociology, 13, 443-464. 